\title{
Efficacy of Miswak (salvadora persica) in preventing dental caries
}

\author{
Fatemeh Ezoddini-Ardakani
}

Department of Oral and maxillofacial radiology, School of Dentistry, Shahid Sadoughi University of Medical Sciences, Yazd, Iran; ezoddini@gmail.com, afsan40@yahoo.co.uk

Received 1 November 2009; revised 5 December 2009; accepted 7 December 2009.

\begin{abstract}
The rate of dental caries and periodontal diseases in the world is still high, regardless of progress in the oral and dental hygiene. The natural toothbrush or chewing stick called "Miswak" has been used since ancient history. In this research the efficacy of Miswak in preventing dental caries was investigated and compared with the efficacy of toothbrush and toothpaste. The analytical and clinical trial method was applied for this research among high school's students in the city of Yazd, Iran, 2006. Three hundred eighty second year's students (190 cases and 190 controls) were examined dentally. Then the Miswak was distributed to the case group and required trainings were given to both groups. After one year, the examinations were repeated. For analyzing the data one-way variance analysis test, Kai square, Paired t-test and two variable analyses were used. In the beginning of this study, there were no significant differences between two groups (cases and controls) regarding their dental situation and the frequency of brushing their teeth ( $p$-value = 0.162 ). In addition, there were no significant differences in DMFT between the two groups. The data collected at the end of the study showed a significant increase in DMFT in the control group ( $p$-value $=0.000$ ). There was $55 \%$ increase in the rate of dental caries in control group compared to case group ( 0.89 before the study and 1.38 after the study). The risk of dental caries for each tooth in control group was 9.35 times more than case group $(9.14 \%$ and $0.98 \%$ respectively). Dental caries rate was detected slightly less in the case group at the end of this study. This might be as a result of the antimicrobial effects of Miswak. A longer study with more cases is needed to prove this suggestion.
\end{abstract}

Keywords: Miswak; Dental Caries; Salvadora Persica; Toothbrush

\section{INTRODUCTION}

Salvadora Persica (S.P.) is a plant that grows in the deserts of the area from west India to Africa. The roots and sticks of S.P. are used widely for cleaning the teeth in these areas. The other names for this plant are Arak tree, Chewing stick, Natural toothbrush and Miswak [1].

Regardless of daily improving dental and oral health in the world the dental caries and gingivitis is increasing due to the widely use of sugar in food, fluoride and calcium deficiency and finally ignoring health care [2]. There are nearly seven plants for this meaning but the most commonly used one is Miswak which is derived from S.P. plant mostly in Saudi Arabia and parts of the Middle East [3]. The values of these sticks are due to their components and cleaning mechanisms. Recently these sticks were recommended as an effective tool for oral health by the World Health Organization (WHO).

The sticks have usually $15 \mathrm{~cm}$ length and $1 \mathrm{~cm}$ diameter (Figure 1). This is why these sticks are called chewing sticks as well. Their pleasant hot taste made them easily chewable. Sometimes a small part of the stick is used as a tooth stick.

Primary analysis showed that S. Persica contains Tri-Methyamin, Salvadrin, Chloride, Fluoride, Silica, Sulfur, Mustard, Vitamin C and a small amount of Saponine Tanin. These components have antibacterial and antifever effects in addition to be against gingival irritation [4]. There are many studies showing that Miswak have strong anti caries effects due to large amounts of fluoride in it. Many dental studies reported antimicrobial activity in derivates from Miswak. In addition, the mechanical cleaning effects of Miswak were investigated and it was reported that the value of chewing sticks is due to their mechanical cleaning [5]. There are many reports showing Miswak is effective in decreasing gingivitis and dental plaques. Elvin-Lewis et al. [6] showed that the dental loss in adults is very low in the countries 


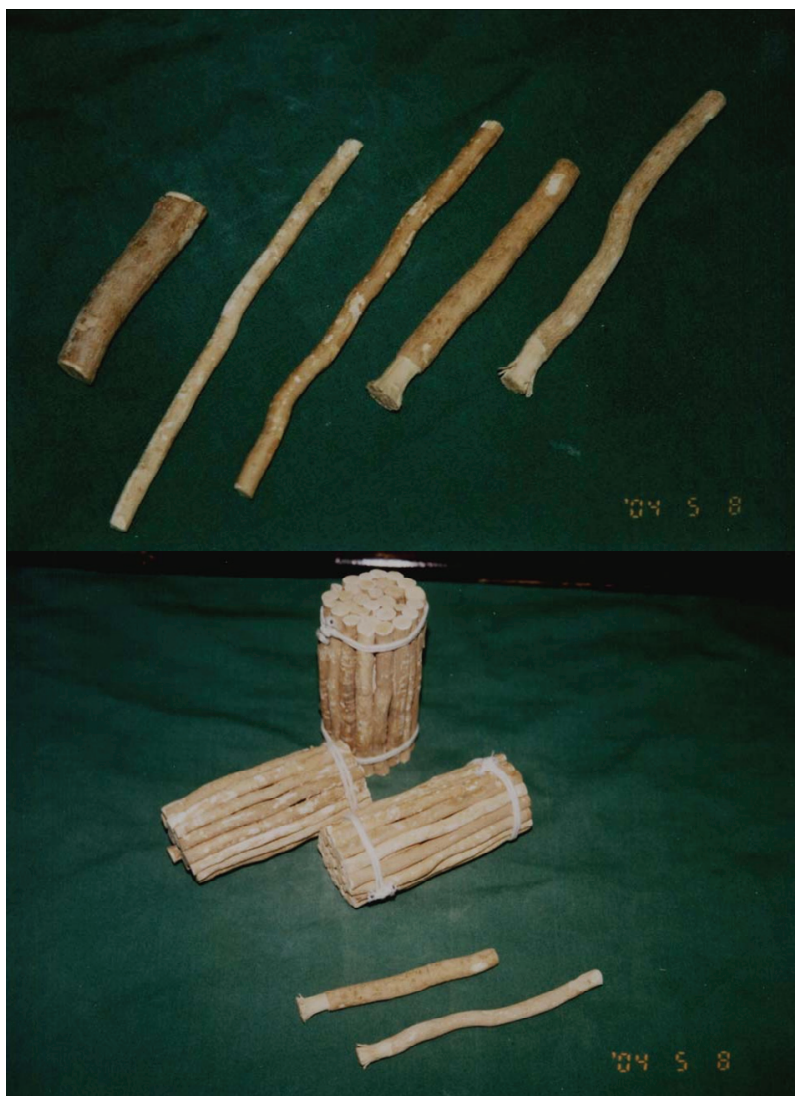

Figure 1. The shape of some chewing sticks.

that Miswak is used widely. Almas, [7] showed amazing antibacterial effects of Miswak on Streptococcus Mutant and Fecalis. Olsson [8] reported that chewing sticks are more effective in decreasing dental caries than toothbrush. Al-lafi and Ababneh [9] investigated antibacterial effects of Miswak in three ways and showed that derivatives if these sticks have strong effects on the growth of Streptococcus and staphylococcus aurous. Danielsen, et al. [10] studied two groups of students in Kenya. One group used chewing sticks plus toothpaste and the other group used only chewing sticks. There were no extra effects in removing dental plaques in the group that used toothpaste in addition to chewing sticks.

The aims of this study were to investigate the effects of Miswak in preventing tooth caries comparing with toothbrush.

\section{MATERIALS AND METHODS}

This study was a clinical trial with before and after design. It was done in 190 cases and 190 controls (95 girls and 95 boys) in the second year students of Yazd high schools. Cluster sampling was used to choose 6 boys and 6 girls high schools in Yazd. Then these high schools were randomly divided into two groups of three high schools each using as case and control groups.
The investigators were chosen among final year dental students. Required training regarding filling questionnaires and dental examination were given to them. The author supervised all the investigation's steps. The materials used by the investigators were explorer, mirror, light, gloves, upper and lower teeth models, Oral-B toothbrush and Miswak. Dentists examined all of the students teeth at the beginning of the study and the number and degree of DMF teeth were recorded in the questionnaires. The degrees of caries were measured by explorer and persons complaints. Even small insertion of the explorer in the teeth recorded as a caries. The degrees of the caries were divided to class I to class VI. After recording the primary data Miswak were given to the case group and the way to use it were trained to the group and ask them to use it two to three times per day. The Miswaks were controlled every three months and the new Miswaks were given to them if it was necessary. While, the toothbrushes were given to control group, and the training was given to them to brush their teeth two to three times per day exactly as it done for the case group.

After one year, the teeth examinations were done the same as the beginning of the study and the data were recorded in the questionnaire. Our data showed the caries rate in the beginning and at the end of the study and because DMFT have no improvement so the differences were considered to be as the results of disease development in the study year.

The data were imported in the EPI 6 software and were analyzed by SPSS 13 version software. For comparing the data one way variance analysis test, ChiSquare, Paired t-test and two variable analyses were used. For comparing the relative risk of disease development in two groups the Relative risk index was used.

\section{RESULTS}

In this research, from the initial 380 students that started this study, 330 students continued it until the end. In case group there were 174 students which used Miswak for one year and 156 students were in the control group which used toothbrush for one year. The trainings and number of brushing teeth per day were the same for two groups. At the beginning of the study the numbers of case and control students were the same (190). This means that 16 students in the case group $(8.4 \%)$ but 34 students in the control group $(17.9 \%)$ did not continue the experiments until the end. The difference is significant $(\mathrm{p}$-value $=0.006)$. This means that the cases which used Miswak have more interest in brushing their teeth than the controls. The odds ratio to discontinue brushing was 2.37 times in control group than this ratio in case group with the confidence interval of 1.21 to 3.72 which is different from number one significantly ( $p$-value $<0.05$ ). 
The same numbers of male and female were chosen at the beginning of this study, but after one year 159 male and 171 female continue the study. This means that the number of cases which abandon the study was more in the male group but this difference is not significant (p-value $=0.068$ ) and the sex ratio in two groups is nearly the same. In addition, the age of all the cases and controls were nearly the same with maximum 6 months difference from the median.

The number of brushing the teeth in two group were the same at the beginning of the study ( $p$-value $=0.162$ ) (Table 1). There were no significant differences regarding DMFT rate between two groups of cases and controls at the beginning of the study (Table 2).

In this study DMFT was used as a dependent variable to investigate the effectiveness of Miswak. The mean DMFT in two groups at the beginning of the study was $3.691 \pm 2.797$ (mean \pm S.D.) with the confidence interval of $95 \%$ from 3.39 to 3.99 . These data shows the efficacy of Miswak in preventing tooth decay (Table 3).

Table 4 shows that the rate of increased DMF in the case group was nearly 10 times this rate in the control group.

Our data showed that at the beginning of the study the incidence of DMF in the case group was more than this in the control group, but after one year (at the end of the study) this incidence in the case group became less than this in the control group (Table 5). The prevalence ratio of decayed teeth in control group compare with case group was 0.89 before the study, but this was 1.38 after the study. These data shows a 55\% increase in the rate of decay in control group compare with the case group. In addition, the relative risk of decay incidence in the control group was 9.35 times this in the case group.

\section{DISCUSSIONS}

The importance of chewing sticks or Miswak was investigated in several studies (11, 12, 13 and 14). Almas, [7] showed that Miswak has antimicrobial effects against Streptococcus Mutants and Fecalis. In addition, Al-Lafi and Ababnch [9] and Almas, et al. [15] studies showed that Streptococcus Fecalis is the most sensitive microorganism affected by Miswak. Our results showed that the rate of carries decreases after using Miswak and this can be due to these antimicrobial effects. Almas and Al-Zeid [16] in a study investigated the antimicrobial effects of Miswak and it's extract specially on Streptococus Mutan and Lacto Basilus. These effects were compares with the effects of toothbrush and normal saline. Their results showed that in Miswak users there was a significant decreases in streptococcus $(p=0.013)$ but not in Lacto Basilus $(\mathrm{p}=0.147)$.
Table 1. The number of brushing per day in the two groups at the beginning of the study.

\begin{tabular}{ccccccc}
\multirow{2}{*}{ Group } & \multicolumn{2}{c}{ Cases } & \multicolumn{2}{c}{ Controls } & \multicolumn{2}{c}{ Total } \\
\cline { 2 - 7 } Brushing/day & No & $\%$ & No & $\%$ & No & $\%$ \\
\hline 3 times & 2 & 1.1 & 2 & 1.3 & 4 & 1.2 \\
2 times & 12 & 6.9 & 18 & 11.5 & 30 & 9.1 \\
1 time & 84 & 48.3 & 71 & 45.5 & 155 & 47 \\
Rarely & 62 & 35.6 & 43 & 27.6 & 105 & 31.8 \\
Never & 14 & 8 & 22 & 14.1 & 36 & 10.9 \\
Total & 174 & 100 & 156 & 100 & 330 & 100 \\
\hline
\end{tabular}

P-value $=0.162$.

Table 2. The teeth situation in the students at the beginning of the study.

\begin{tabular}{|c|c|c|c|c|c|}
\hline \multirow{2}{*}{ No } & \multicolumn{2}{|c|}{ Cases $(\mathrm{No}=174)$} & \multicolumn{2}{|c|}{ Controls $(\mathrm{No}=156)$} & \multirow{2}{*}{$\mathrm{p}$-value } \\
\hline & Mean & S.D. & Mean & S.D. & \\
\hline \multicolumn{6}{|l|}{ Filled teeth } \\
\hline One side & 0.79 & 1.81 & 0.54 & 1.47 & 0.176 \\
\hline Two sides & 0.1 & 0.52 & 0.08 & 0.32 & 0.767 \\
\hline Three sides & 0.06 & 0.375 & 0 & 0 & 0.036 \\
\hline \multicolumn{6}{|l|}{ Decay teeth } \\
\hline Class I & 2.36 & 2.18 & 2.41 & 2.14 & 0.366 \\
\hline Class II & 0.16 & 0.47 & 0.16 & 0.461 & 0.99 \\
\hline Class III & 0.02 & 0.13 & 0.05 & 0.3 & 0.17 \\
\hline Class IV & 0 & 0 & 0.02 & 0.18 & 0.156 \\
\hline Class V & 0.01 & 0.08 & 0.02 & 0.18 & 0.364 \\
\hline Class VI & 0.01 & 0.11 & 0 & 0 & 0.18 \\
\hline Missing teeth & 0.13 & 0.44 & 0.17 & 0.41 & 0.39 \\
\hline
\end{tabular}

Table 3. Comparison of the differences between DMF in two groups before and after the study.

\begin{tabular}{lccccccccc}
\hline \multirow{2}{*}{ Troup } & \multicolumn{6}{c}{ Case No $=174$} & \multicolumn{6}{c}{ Control No $=156$} \\
\cline { 2 - 9 } & $\mathrm{X}$ & S.D. & Min & Max & X & S.D. & Min & Max & p-value \\
\hline Before & 3.9 & 2.89 & 0 & 14 & 3.46 & 2.68 & 0 & 13 & 0.147 \\
After & 4.14 & 3.05 & 0 & 17 & 5.7 & 3 & 0 & 16 & 0.000 \\
p-value & & 0.000 & & & 0.000 & & \\
\hline
\end{tabular}

Table 4. The difference between DMF in each group.

\begin{tabular}{lcccc}
\hline Group & No & $\begin{array}{l}\text { Mean of increase } \\
\text { during 1 year }\end{array}$ & S.D. & p-value \\
\hline Case & 174 & 0.2356 & 0.523 & 0.000 \\
Control & 156 & 2.2436 & 1.188 & 0.000 \\
\hline
\end{tabular}


Table 5. Prevalence and incidence of decay in two groups.

\begin{tabular}{lcccccccc}
\hline \multirow{2}{*}{ Prevalence } & \multicolumn{3}{c}{ Teeth No in Case group } & \multicolumn{5}{c}{ Teeth No in Control group } \\
\cline { 2 - 8 } & Total & Decayed & $\%$ & Total & Decayed & $\%$ & p-value \\
\hline Before & 4872 & 679 & 13.94 & 4368 & 539 & 12.34 & 0.059 \\
After & 4872 & 720 & 14.78 & 4368 & 889 & 20.35 & 0.00 \\
$\begin{array}{l}\text { One year } \\
\text { incidence }\end{array}$ & 4193 & 41 & 0.98 & 3829 & 350 & 9.14 & 0.00 \\
\hline
\end{tabular}

Wolinsky et al. [17] showed that S.P. decreases the ability of some Streptococcus to colonize on teeth surfaces. Bearing in mind that the cause of tooth decay is acid secretion by microorganisms, the decreases in the rate of caries in this study and also low rate of DMF in the countries which use Miswak can be due to this ability of S.P.

Elvin-lewis et al. [6] and Almas [7] suggested that the antibiotic effects detected in S.P. may have interaction with bacteria and prevent their attachment. The other component of Miswak with possible interaction with bacterial glycolytic enzyme and their acids or intracellular polysaccharides products is Fluoride. Furthermore, Benzylisothiocyanate (BIT) that is naturally a component of S.P. acts as inhibitor of bacterial growth and their acidic products [18]. Chawla [19] showed that some kinds of chewing sticks such as Neem, S.P. and Acaccia Arabica have reasonable amounts of fluoride. They showed that Miswak sticks from S.P. tree have significant antimicrobial effects on streptococcus mutants, streptococcus mitis and staphylococcus. Darout et al. [20] studied the caries and periodontal situation of adults Sudanese using either habitual Miswak or Toothbrush. They suggested using Miswak in developing world because of its availability and cheap price. In our study as well the effects of Miswak were significant and every three months that we were going to the schools to deliver new Miswak sticks to the students their excitement in requesting Miswak was interesting.

At the end of our study, the Miswak has been used more frequently in the Miswak users than toothbrush in the other group. This difference cannot be due to the training, because both groups have the same trainings. In addition our study showed that the rate of DMF which was the same in both groups increased significantly in the toothbrush users compared with Miswak users. This difference can be because of two reasons; 1/Miswak users used Miswak more frequently and 2/Miswak has antimicrobial effects plus fluoride and calcium.

Faiez [21] reviewed the effects of Miswak. Many researchers believed that the efficacy of S.P. is because of its mechanical action while the others believe that Miswak is a natural source for topical fluoride.

About half of the people in Saudi Arabia use Miswak.
Magbool [22] showed that only $12.5 \%$ of students are Caries free in Saudi Arabia and the rate of tooth decay is $48 \%$ in 6 and 7 years old age group but this rate decreases and is only $1.03 \%$ in 16 and 17 years old age group. We showed that the prevalence of caries in case group is less than this rate in control group and this can be as a result of using Miswak.

Norton and Addy [23] did a pilot and cross sectional study among adults in Ghana. They showed that the rate of plaque and carries in Miswak users was less than this rate among non users.

In the other studies among Ethiopian and Nigerian students and Saudi Arabian dental students, using Miswak and toothbrush was compared. These comparisons showed that Miswak was more effective than toothbrush in removing plaque $[6,23,24]$. These differences can be related to the frequency and duration of brushing, experiences in using Miswak, motivation and supervision.

One of the specifications of Miswak is its straight shape that is a disadvantage because it cannot clean linguinal sides of the teeth.

Miswak contains nearly $1.02 \mu \mathrm{g} / \mathrm{g}$ total fluoride. Chawla showed that the chewing sticks of S.P., Neemkikar, Walnut and Pekujebu have 2.8, 1.0, 0.5 and 0.2 $\mu \mathrm{g} / \mathrm{ml}$ fluorides respectively [19]. Miswak releases a significant amount of calcium and phosphor in water and these elements are necessary for remineralization. Crystallographic studies with fluorescence and x-ray microanalysis showed that S.P. sticks have more calcium and phosphor [24].

Recently S.P. extract was used in some toothpastes like Ouali Meswak, Pharba, Sarakan, Backenham UK, Basaraj and Epident [25]. Miswak extract and $0.8 \%$ monoflourophosphate sodium) compared with Oral-B toothpaste (containing only $0.8 \%$ monoflourophosphate sodium) in dental students. Their results showed that the toothpaste containing Miswak extract significantly was more effective in removing dental plaques compare with Oral-B toothpaste. It was also showed that Miswak has antidecay effects because of its fluoride contents. In addition, the hot taste of Miswak plus the chewing effects of the stick can increase the salvia secretion in the mouth and therefore increase its buffering capacity [21]. In our study these factors can be effective as well.

Sofrata reported that the chewing stick (Miswak) is used for oral hygiene in many parts of the world. In addition to the mechanical removal of plaque, an antibacterial effect has been postulated. Miswak embedded in agar or suspended above the agar plate had strong antibacterial effects against all bacteria tested. The antibacterial effect of suspended Miswak pieces suggests the presence of volatile active antibacterial compounds [26].

Almas concluded that toothbrushes and Miswak (chewing sticks) are widely used for the mechanical removal of plaque [27]. 
Sofrata reported that the difference in plaque $\mathrm{pH}$ between Miswak extract and water rinse was statistically significant at $30 \mathrm{~min}(\mathrm{p}<0.001)$ [28]. Rinsing with Miswak extract stimulated parotid gland secretion $(\mathrm{p}<$ 0.01). Miswak extract raised the plaque $\mathrm{pH}$, suggesting a potential role in caries prevention

\section{CONCLUSIONS}

Our study showed that Miswak effectively prevented dental caries in high school students. Conducting some studies on antimicrobial and silicate effects of Miswak are suggested.

\section{REFERENCES}

[1] Galati, E.M., Monforte, M.T., Forestieri, A.M., Miceli, N., Bade, A. and Trovato, A. (1999) Salvadora persica L: Hypolipidemic activity on experimental hypercholesterolemia in rat. Phytomedicine, 6(3), 181-185.

[2] Kimery, M.J. and Stallard, R.E. (1992) The evolutionary development and contemporary utilization of various oral hygiene procedures. Periodontal Abstracts, 16, 90-97.

[3] Abderahim, M. and Jurner, J.E. (1983) In vitro evaluation of Saudi Arabian tooth tree (Salvadoran Persica). Odontostomatological Tropicale, 613, 145-148.

[4] Wolinsky, L.E. and Sote, E.O. (1984) Isolation of natural plaque inhibiting substances from Nigerian chewing sticks. Caries Research, 18(3), 216-225.

[5] Akpata, E.S. and Akinrimisi, E. (1977) Antibacterial activity of extracts from some African Chewing sticks. Oral Surgery, 44(5), 717-722.

[6] Elvin-Lewis, M., Hall, J.B. and Adu-uta, M. (1980) The dental health of chewing stick users of southern Ghana, preliminary finding. Journal of Preventive Dentistry, 6, 151-154.

[7] Almas, K. (1999) The antimicrobial effects of extracts of Azadirachta Indica (NEEM) and Salvadora Persica (Arak) chewing sticks. Indian Journal of Dental Research, 10(1), 23-26.

[8] Olsson, B. (1978) Efficiency of traditional chewing sticks in oral hygiene programs among Ethiopian Schoolchildren. Community Dentistry and Oral Epidemiology, 6, 105-109.

[9] Al-lafi, T. and Ababneh, H. (1995) The effect of the extract of the Miswak (chewing sticks) used injordan and the middle east on oral bacteria. International Dental Journal, 45(3), 218-222.

[10] Danielsen, B.O., Vibeke, B., Manji, F. and Fejerskov, O. (1989) Chewing sticks, tooth paste and plaque removal. Acta Odontol Scand, 47, 121-125.

[11] Akhtar, M. and Ajmal, M. (1981) Significance of chewing sticks (Miswak) in oral hygiene from a pharmacological viewpoint. Journal of Pakistan Medical Association, 31(4), 89-95.

[12] Farooqi, M.I.H. and Srivastava, J. (1983) The tooth tree
(Salvadora persica). Quarterly Journal of Crude Drug Research, 81(4), 1297-1299.

[13] El-Mostehy, M.R., Al-Jassem, A.A., Al-Yassin, I.A., et al. (1983) Miswak as an oral health device preliminary chemical and clinical evaluation. Hamdard, 26, 41-50.

[14] Khoory, T. (1999) The use of chewing sticks in preventive oral hygiene. Clinic Preventive Dentistry, 5, 11-14.

[15] Almas, K., Al-Bagieh, N. and Akpata, E.S. (1997) In vitro antimicrobial effects of freshly cut and 1-month old miswac (chewing stick). Biomedical Letters, 56, 145-149.

[16] Almas, K. and Al-Zeid, Z. (2004) The immediate antimicrobial effect of a toothbrush and Miswak on cariogenic bacteria: A clinical study. Journal of Contemporary Dental Practice, 5(1), 105-114.

[17] Wolinsky, L.E., Mania, S., Nachnani, S., et al. (1996) The inhibiting effect of aqueous Azadirechta indica (Neem) extract upon bacterial properties influencing in vitro plaque formation. Journal of Dental Research, 75(2), 816822.

[18] Al-Bagieh, N.H. and Weinberg, E. (1989) Benzylisothicyanate: A possible agent for controlling dental caries. Microbios, 39, 143-151.

[19] Chawla, H.S. (1983) A new natural source for topical fluoride. Journal of the Indian Dental Association, 55 (10), 419-422.

[20] Darout, I.A., Albandar, J.A. and Nils, S. (2000) Periodontal status of adult Sudanese habitual users of Miswac chewing sticks or toothbrushes. Acta Odontol Scand. 58, 31-37.

[21] Faiez, N.H. (1995) Miswac: The natural toothbrush. The Journal of clinical Dentistry, 8(5), 125-129.

[22] Magbool, G. (1992) Prevalence of dental caries in school children in Al-Khobar Saudi Arabia. Journal of Dentistry for Children, 59(5), 384-386.

[23] Norton, M.R. and Addy, M. (1989) Chewing sticks versus toothbrushes in West Africa. A pilot study. Clinical Preventive Dentistry, 11(3), 11-13.

[24] Char, D.C.N., Dogao, A.U. and Dogan, M.M. (1987) SEM, XRF. and EMPA evaluation of Middle Eastern toothbrush "Salvadora persica". Journal of Electron Microscopy Technology, 5, 145.

[25] Guile, E.E., Al-Shammery, A.R. and El-Backly, M.N. (1996) Oral health survey of Saudi Arabia: Oral health knowledge attitudes and practice among adults. Journal of Dental Research, 75, 1276.

[26] Sofrata, A.H., Claesson, R.L., Lingström, P.K. and Gustafsson, A.K. (2008) Strong antibacterial effect of Miswak against oral microorganisms associated with periodontitis and caries. Journal of Periodontology, 79(8), 1474-1479.

[27] Almas, K. (2002) The effect of Salvadora persica extract (Miswak) and chlorhexidine gluconate on human dentin: A SEM study. The Journal of Contemporary Dental Practice, 3(3), 27-35.

[28] Sofrata, A., Lingström, P., Baljoon, M. and Gustafsson, A. (2007) The effect of Miswak extract on plaque $\mathrm{pH}$. An in vivo study. Caries Research, 41(6), 451-454. 